\title{
Original
}

\section{Physical Properties and Hydroxyapatite Formation of Fast Self-setting Biphasic Calcium Phosphate Cement}

\begin{abstract}
Akiyoshi Sugawara ${ }^{1,2)}$
1) Sugawara Dental Clinic, Tokyo, Japan

2) Nihon University School of Dentistry, Tokyo, Japan

(Accepted for publication, June 7, 2020)

Abstract: Biphasic calcium phosphate (BCP) cement, consisting of an $\alpha$-tricalcium phosphate-tetracalcium phosphate as the only solid phase and a calcium phosphate solution (Ca-P soln) as the liquid phase, was formerly reported. The BCP cement was easy to prepare, and was expected to show desired handling properties and to form hydroxyapatite (HA) for clinical applications. The objective of the study was to evaluate physical properties and HA formation of the BCP cement. The solid phase of the cement was a $\mathrm{BCP}(\mathrm{Ca} / \mathrm{P}$ of 1.8$)$ prepared in a furnace and ground to a median size of $9.96 \mu \mathrm{m}$. The liquid phase of the $\mathrm{BCP}$ cement consisted of an acidic Ca-P soln, which was produced by mixing phosphoric acid with calcium carbonate $\left(\mathrm{CaCO}_{3}\right)$ and diluted 3.0-fold, 3.5-fold, 4.0-fold with $\mathrm{H}_{2} \mathrm{O}$. Additionally, trisodium citrate anhydrous and polyvinylpyrrolidone were included as a water reducing agent and washout resistance enhancer, respectively. Cement powder and liquid were mixed $(\mathrm{P} / \mathrm{L}=3.0)$ to produce samples for setting time, diametral tensile strength (DTS) and compressive strength (CS) measurements. X-ray powder diffraction (XRD) analyses and microscopic observations by FE-SEM and atomic force microscope (AFM) were also performed to identify HA conversion in set samples with time chronologically. BCP cement showed good washout resistance when immersed in water. The setting times $(\mathrm{n}=5)$ were 3.0 -fold: $5.24 \pm 0.01 \mathrm{~min}, 3.5$-fold: $7.39 \pm 0.01 \mathrm{~min}$ and 4.0 -fold: $9.06 \pm 0.01 \mathrm{~min}$ at $25 \pm 1{ }^{\circ} \mathrm{C}$. Differences were apparently existed between each sample $(p<0.05)$. One-day wet DTS ( $\mathrm{n}=5$ ) values were 3.0-fold: $7.07 \pm 0.51 \mathrm{MPa}$, 3.5-fold: $5.98 \pm 0.91 \mathrm{MPa}$ and 4.0 -fold: $5.07 \pm 0.51 \mathrm{MPa}$ and CS $(\mathrm{n}=5)$ values were 3.0 -fold: $46.58 \pm 3.21 \mathrm{MPa}, 3.5$-fold: $47.75 \pm 2.55 \mathrm{MPa}$ and 4.0 -fold: $45.53 \pm 1.97 \mathrm{MPa}$. No difference was exhibited between DTS results for each sample except between 3.0-fold and 4.0-fold samples $(p<0.05)$, and CS results showed no apparent difference existed among all samples $(p<0.05)$. XRD analyses showed that BCP cement mostly converted to HA and microscopic features exhibited that HA crystals were clearly observed on surfaces of the BCP-cement at 24 hours after mixing. The newly developed BCP cement was found to have adequate physical properties and HA formation for clinical use.
\end{abstract}

Key words: BCP cement, Physical property, HA conversion

\section{Introduction}

A number of calcium phosphate cements (CPCs) have been used for clinical treatments for almost three decades with satisfactory results. In addition to high biocompatibility and osteoconductivity, many advantages of CPCs as a class of bone graft substitute material are derived from their self-hardening properties. The pasty consistency and washout resistance of CPCs allows close adaption or direct contact to the irregular contours of bone surfaces. However, there have been concerns of difficult handling properties and insufficient physical properties to allow perfect placement and shaping of the graft. Thus, CPCs may be made more clinically useful by improvements in their handling and physical properties.

Furthermore, commercially available CPCs consist of two or more calcium phosphates, calcium-containing or phosphate-containing compounds as the solid phase and a sodium phosphate solution or organic acid, such as citric, tartaric, malic, lactic acid, as the liquid phase ${ }^{1-5)}$. These CPC's powder compounds, which need to be manufactured sepa-

Correspondence to: Dr. Akiyoshi Sugawara, Sugawara Dental Clinic, 1-57-5 Sasazuka, Shibuya-ku, Tokyo, 151-0073 Japan; Tel: +81-3-3378-3929; Fax: +81-3-3378-3309; E-mail: aki@dr-sugawara.com rately and each ground to the required particle size distribution, are then thoroughly blended to produce a homogeneous mixture. The cement powders exhibited poly-modal size distributions. Therefore, the handling, hardening, mechanical, and most importantly in vivo properties of $\mathrm{CPC}$ products depend strongly on the composition and size distributions of the CPC powders. In addition, the CPC, the powder was consisted of an $\alpha$-tricalcium phosphate ( $\alpha$-TCP)-tetracalcium phosphate (TTCP) at different molar ratio and the liquid consisted of a sodium dihydrogen phosphate, was previously reported ${ }^{5}$. However, the cement took a few weeks to cure and showed insufficient physical strength for clinical use. Even after full cure, most of the hardened cement mass still did not convert to hydroxyapatite $(\mathrm{HA})^{5,6)}$.

Biphasic calcium phosphate cement (BCP-cement), consisting of an $\alpha$-TCP- TTCP as the only solid phase and a calcium phosphate solution (Ca-P soln) as the liquid phase, was previously reported ${ }^{6-16)}$. The powder phase of BCP consists of a single solid-solution compound with a mono-modal size distribution. The compound is synthesized in a single manufacturing process, and ground to a single size distribution. When the hardening reaction of the $\mathrm{BCP}$ cement proceeded, the $\mathrm{BCP}$ cement mostly converted to HA, which is the main inorganic component of 
J.Hard Tissue Biology Vol. 29(3): 173-182, 2020

Table 1. Materials used in this study

\begin{tabular}{l|l}
\hline \multicolumn{1}{c|}{ Materials } & \multicolumn{1}{c}{ Manufactures } \\
\hline Powder phase : & Taihei Chemical Industrial Co. Ltd., Osaka, Japan \\
Tetracalcium Phosphate $(\mathrm{TTCP}): \mathrm{Ca}_{4}\left(\mathrm{PO}_{4}\right)_{2} \mathrm{O}$ & Taihei Chemical Industrial Co. Ltd., Osaka, Japan \\
$\alpha$-Tricalcium Phosphate $(\alpha-\mathrm{TCP}): \mathrm{Ca}_{3}\left(\mathrm{PO}_{4}\right)_{2}$ & Taihei Chemical Industrial Co. Ltd., Osaka, Japan \\
Dicalcium Phosphate Anhydrous $(\mathrm{DCPA}): \mathrm{CaHPO}_{4}$ & Wako Pure Chemical Industries, Ltd., Osaka, Japan \\
Trisodium Citrate Anhydrous $(\mathrm{Na} 3 \mathrm{Cit}): \mathrm{Na}_{3}\left(\mathrm{C}_{3} \mathrm{H}_{5} \mathrm{O}(\mathrm{COO})_{3}\right)$ & Wako Pure Chemical Industries, Ltd., Osaka, Japan \\
Calcium Carbonate: $\mathrm{CaCO}_{3}$ & \\
\hline Liquid phase : & BASF Japan Ltd., Tokyo, Japan \\
Polyvinylpyrrolidone- $\mathrm{k}_{2} 5(\mathrm{PVP}-\mathrm{k} 25):\left(\mathrm{C}_{6} \mathrm{H}_{9} \mathrm{NO}\right) \mathrm{n}$ & Wako Pure Chemical Industries, Ltd., Osaka, Japan \\
Phosphoric Acid: $\mathrm{H}_{3} \mathrm{PO}_{4}$ & Wako Pure Chemical Industries, Ltd., Osaka, Japan \\
Calcium Carbonate: $\mathrm{CaCO}_{3}$ & Nichi-Iko Pharmaceutical Co., Ltd. \\
Sterile purified water: $\mathrm{H}_{2} \mathrm{O}$ &
\end{tabular}


Figure 1. Schematic drawing and particle size distribution of BCP powder particles. The powder phase of BCP cement was a solid solution of TTCP and $\alpha$-TCP. BCP powder showed mono-modal particle distribution, and the median particle size of the powder was $9.96 \mu \mathrm{m}$.

bone, as the final product within 24 hours after mixing ${ }^{6-10,16)}$. Our former study reported that the $\mathrm{BCP}$ cement had excellent biocompatibility and osteoconductivity compared to the control cement. Micro-CT results showed the cement maintained its original graft shape and adaptability through the entire experimental period, and also exhibited excellent washout resistance to bodily fluid when applied to bone defects. These results indicated that the $\mathrm{BCP}$ cement was successfully retained and had adequate physical properties after the filling.

Physical properties were essentially related to clinical application, and HA conversion was directly related to biocompatibility and bone formation. The purpose of this study was to examine washout resistance, physical properties, HA conversion and microscopic observations of the BCP cement.

\section{Materials and Methods}

The materials used in this study are shown in Table 1.

The powder phase of BCP cement was a solid-solution of $\alpha$-TCPTTCP. It was prepared by heating a mixture of dicalcium phosphate anhydrous (DCPA) and calcium carbonate $\left(\mathrm{CaCO}_{3}\right)$ in a furnace, and ground to a mono-modal size distribution with median size of $9.96 \mu \mathrm{m}$. Solid-solutions with compositions ranging from $95 \% \alpha$-TCP/5\% TTCP to $5 \% \alpha-\mathrm{TCP} / 95 \% \mathrm{TTCP}$ are contemplated. In general, the corresponding molar $\mathrm{Ca} / \mathrm{P}$ ratios of the powder range from 1.52 to 1.97 , and a $\mathrm{Ca} / \mathrm{P}$ ratio of 1.8 was used in this study. The scheme and the distribution of BCP powder particle are shown in Fig. 1. The liquid phase of BCP cement consisted of an acidic Ca-P soln ( $\mathrm{pH} 2.1)$, which was produced by mixing phosphoric acid with $\mathrm{CaCO}_{3}$ and diluted 3.0-fold, 3.5-fold and 4.0-fold with $\mathrm{H}_{2} \mathrm{O}$, and then used as the cement liquid.

Additionally, tri-sodium citrate anhydrous $\left(\mathrm{Na}_{3} \mathrm{Cit}\right)$ in the powder phase and polyvinylpyrrolidone-k25 (PVP-k25) in the liquid phase were included as a water reducing agent and a washout resistance enhancer, respectively ${ }^{6-16)}$. The samples were prepared by mixing BCP powder with the cement liquid at a $\mathrm{P} / \mathrm{L}$ ratio of 3.0. The components and the setting reaction of the $\mathrm{BCP}$ cement are shown in Fig. 2. The total amount of $\mathrm{Na}_{3} \mathrm{Cit}$ in the sample was adjusted to $1.5 \mathrm{~mol} / \mathrm{l} . \mathrm{Na}_{3} \mathrm{Cit}$ achieved high zeta-potentials of CPCs caused by adsorption of multiple charged citrate ions at the solid-liquid interface, enabling the effective dispersion of cement particles ${ }^{6-16)}$. Using the $\mathrm{Na}_{3}$ Cit solution decreased the viscosity, achieved injectability, and improved the strength of the cement paste when used as a bone graft material ${ }^{6,11-18)}$. In this study, the powder contained $\mathrm{Na}_{3} \mathrm{Cit}$ and each liquid contained $0.75 \mathrm{wt} \%$ of PVP-k25. Ca-P solns of the 3.0-fold, 3.5-fold and 4.0-fold dilution with $\mathrm{H}_{2} \mathrm{O}$ were used for physical property and XRD analyses of the BCP cement, and microscopic observations were performed for the BCP cement using Ca-P soln of 3.5-fold dilution with $\mathrm{H}_{2} \mathrm{O}$.

The samples were prepared by mixing $\mathrm{BCP}(\mathrm{Ca} / \mathrm{P}$ ratio $=1.8)$ powder with the cement liquid for $30 \mathrm{sec}$ at $\mathrm{P} / \mathrm{L}$ ratio of $3.0^{6-10)}$, and then used for washout resistance, setting time (Gilmore needle), diametral tensile strength (DTS) / compressive strength (CS) measurements, XRD analyses and microscopic observations. Experimental procedures are described as bellow.

\section{Washout resistance and setting time}

For the measurement of washout resistance, 3.0-fold/3.5-fold/4.0- 


\section{- Components}

\begin{tabular}{|l|}
\hline Liquid \\
pH 2.1 calcium phosphate solution \\
( $\mathrm{Ca}$-P soln), with 3.0 -fold,3.5-fold,4.0-fold \\
dilution with $\mathrm{H}_{2} \mathrm{O}$, containing 0.75 wt\%PVP \\
\hline
\end{tabular}

\section{- Setting reactions}

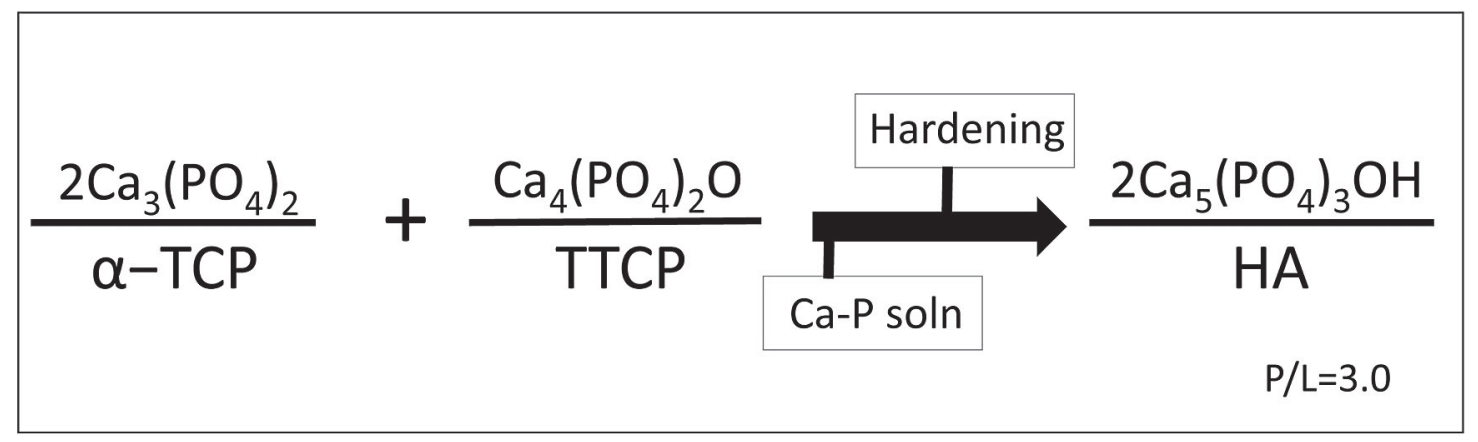

Figure 2. Components and setting reaction of the BCP cement. Three kinds of Ca-P soln., diluted with 3.0-fold, 3.5-fold and 4.0-fold $\mathrm{H}_{2} \mathrm{O}$, were used as the cement liquid. $\mathrm{Na}_{3} \mathrm{Cit}$ in the powder phase and PVP-k25 in the liquid phase were included as a water reducing agent and a washout resistance enhancer, respectively. During the setting reaction proceeded, the BCP cement mostly converted to HA as a final product.

fold cement pastes were manually shaped into a ball and immersed in water at 3 min after mixing. The samples were visibly checked for shape at $10 \mathrm{~min}$ after mixing. The samples were also taken out from water by tweezers and their shape-integrities were observed at 15 min after mixing. The cement was considered to pass the washout resistance test if the paste sample kept original shape and did not visibly disintegrate in water.

The setting time of 3.0-fold/3.5-fold/4.0-fold cement paste was estimated by the results of a Gilmore needle method test. The Gilmore needle method test was performed using a needle with a tip diameter of 2.12 $\mathrm{mm}$ loaded with $453.5 \mathrm{~g}$. The hand-mixed pastes were filled into the mold ( $2.0 \mathrm{~cm}$ in diameter, $3 \mathrm{~mm}$ in thickness) on a glass plate, and were stored in $50 \%$ relative humidity at $23 \pm 1^{\circ} \mathrm{C}$. In this method, the cement was considered to set when the needle with the load failed to make a perceptible indentation on the surface. The data of each sample was used to calculate the group mean $( \pm \mathrm{SD})$. A Tukey-Kramer test was used to establish statistical significance $(\mathrm{p}<0.05)$.

\section{Mechanical strengths}

The 3.0-fold $/ 3.5$-fold $/ 4.0$-fold cement pastes were filled into a glass mold (6.0 $\mathrm{mm}$ in diameter, $12.0 \mathrm{~mm}$ in thickness) and kept in $100 \%$ humidity at $37^{\circ} \mathrm{C}$ for $2 \mathrm{~h}$. After removal from the mold, each sample was stored in $30 \mathrm{ml}$ of $\mathrm{H}_{2} \mathrm{O}$ for $22 \mathrm{~h}$ and used for CS and DTS measurements immediately. The mechanical strength of the sample was measured using a Universal Testing Machine (TG-5KN, Instron Japan Co. LTD, Kanagawa, Japan) at cross head speed of $1 \mathrm{~mm} / \mathrm{min}$. DTS values were calculated using the equation; DTS $(\mathrm{MPa})=2 \mathrm{P} / \pi \mathrm{DH}$, and $\mathrm{CS}$ values were calculated using the equation $\mathrm{CS}(\mathrm{MPa})=2 \mathrm{P} / \mathrm{DH}$. The data of each sample were used to calculate the group mean $( \pm \mathrm{SD})$ and underwent a Tukey-Kramer test for individual comparison with a 0.05 level of significance. (P: load, D: diameter, H: height)

\section{$X$-ray diffraction (XRD) analysis}

HA formation of the BCP cement was examined by powder X-ray diffraction (XRD) analysis ${ }^{9,10)}$. The 3.0-/3.5-fold/4.0-fold cement pastes were filled into a glass mold $(\phi 6.0 \mathrm{~mm} \times \mathrm{H} 12.0 \mathrm{~mm})$ and kept in $100 \%$ humidity at $37^{\circ} \mathrm{C}$ for $2 \mathrm{~h}$, and then removed from the mold and stored in $30 \mathrm{ml}$ of $\mathrm{H}_{2} \mathrm{O}$ for $22 \mathrm{~h}$. After storage, the samples were dehydrated in acetone for $1 \mathrm{~h}$ and dried in the desiccator for $23 \mathrm{~h}$, and then ground to fine powder by mortar and pestle for XRD. XRD analyses of the 3.5fold samples at $6,12,24$ and $48 \mathrm{~h}$ were also performed to examine chronological HA conversion.

Powder XRD patterns, obtained with a powder x-ray diffractometer (Multi Flex, Rigaku Corporation, Tokyo, Japan), were used to determine phase compositions of the hardened samples. The XRD patterns were recorded with use of a vertical-mounted diffractometer system with graphite-monochromatized $\mathrm{CuK}_{\alpha}$ radiation $(\lambda=0.154 \mathrm{~nm})$ generated at 40 $\mathrm{kV}$ and $20 \mathrm{~mA}$, and scanning speed $2 \% \mathrm{~min}$. The sample was scanned from 10 to 60 degrees $2 \theta$ in a continuous mode, and peak intensities were recorded on a computer. Analysis of the detected diffraction pattern was performed in comparison with standard powder X-ray diffraction data (Powder Diffraction File: PDF) for each substance, and the chronological formation of HA from $\alpha$-TCP/TTCP as the original substance was confirmed.

\section{Microscopic observations}

The 3.5-fold samples were prepared by same procedures as for the XRD samples until drying in the desiccator, and then were broken for fractures. Observations of the fracture surface of the samples were conducted by field emission-scanning electron microscope (FE-SEM) and atomic force microscope (AFM).

FE-SEM observations for $24 \mathrm{~h}$ and $48 \mathrm{~h}$ samples were performed us- 
ing SEM (SU8020, Hitachi high technologies, Tokyo, Japan) at an accelerating voltage of $07 \mathrm{~V}$. Prior to the observation, samples were fixed on stubs without sputtered coating. Observations were carried out up to where the crystalline form of HA could be distinguished. AFM observations for $24 \mathrm{~h}$ and $48 \mathrm{~h}$ samples were carried out in a completely non-contact state using AFM (NX-20 type, Park Systems Japan, Tokyo, Japan) and cantilever (OMCL-AC160TS, Park Systems Co. Japan, Tokyo, Japan), under conditions of $256 \times 256$ and $512 \times 512$ pixels and a scan rate of $0.2-1 \mathrm{~Hz}$. Firstly, observations of the surface of each sample were carried out in the range of $20 \times 10 \mathrm{um}$, then observations were performed while sequentially increasing the magnification ratio for parts where it was considered to be necessary. Observations were carried out up to the range of magnification whereby objects of about $100 \mathrm{~nm}$ could be identified and where the crystalline form of HA could be distinguished. Also, differential image Enhanced Color (EC) displays were made for the purpose of confirming the parts that were difficult to distinguish due to large surface forms and the presence of unevenness etc., and for clarifying three-dimensional discrimination in the AFM image. Furthermore, the surface roughness corresponding to each AFM image was given by line profile.

\section{Results}

\section{Washout resistance and setting time}

Three kinds of Ca-P soln diluted with 3.0-fold, 3.5-fold and 4.0-fold $\mathrm{H}_{2} \mathrm{O}$, were used as cement liquid. After the mixing, all BCP cement pastes were an injectable phase through a cannula ( $2 \mathrm{~mm}$ in diameter), then became a moldable phase with shape integrity, and hardened stiffly. Fig. 3 shows the washout resistance results for the cement pastes. All samples showed that no noticeable disintegration and negligible debris were observed at $10 \mathrm{~min}$ after the mixing (A). All samples set into solid masses, so the samples were taken out from water by tweezers without any collapse. The samples were observed in dry condition at $15 \mathrm{~min}$ after mixing (B). Observations for the samples, which were continuously preserved in water, made at $24 \mathrm{~h}$ later were also the same as (A), with
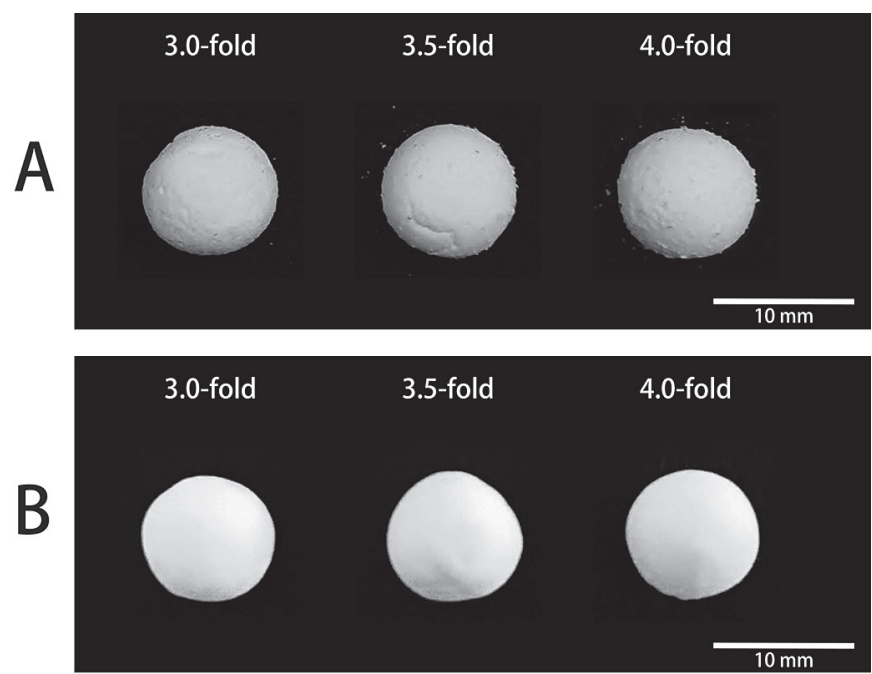

Figure 3. Washout resistance and handling properties of the $\mathrm{BCP}$ cement. All samples showed that no noticeable disintegration and negligible debris were observed at $10 \mathrm{~min}$ after the mixing (A). All samples set into solid masses, so the samples were taken out from water by tweezers without any collapse. The samples were observed in dry condition at $15 \mathrm{~min}$ after mixing (B). The cement was considered to pass the washout resistance test if the paste sample kept original shape and did not visibly disintegrate in water. no further disintegration from the $10 \mathrm{~min}$-samples.

Following previously studies ${ }^{18-20)}$, the sample was considered to pass the washout resistance test if the paste did not visibly disintegrate. Therefore, all BCP cements were considered to have excellent washout resistance when preserved in water.

The setting time of each cement paste is shown in Fig. 4. The cement showed injectable phase initially and exhibited moldable phase, and then hardened stiffly. The setting time of each sample $(\mathrm{n}=5)$ to harden was 3.0-fold: $5.24 \pm 0.006 \mathrm{~min}, 3.5$-fold: $7.39 \pm 0.006 \mathrm{~min}$, and 4.0fold: $9.06 \pm 0.006 \mathrm{~min}$ at $25 \pm 1^{\circ} \mathrm{C}$. The 3.0 -fold sample showed the shortest setting time until hardening among all samples, and there were apparent differences between each sample in hardening $(p<0.05)$.

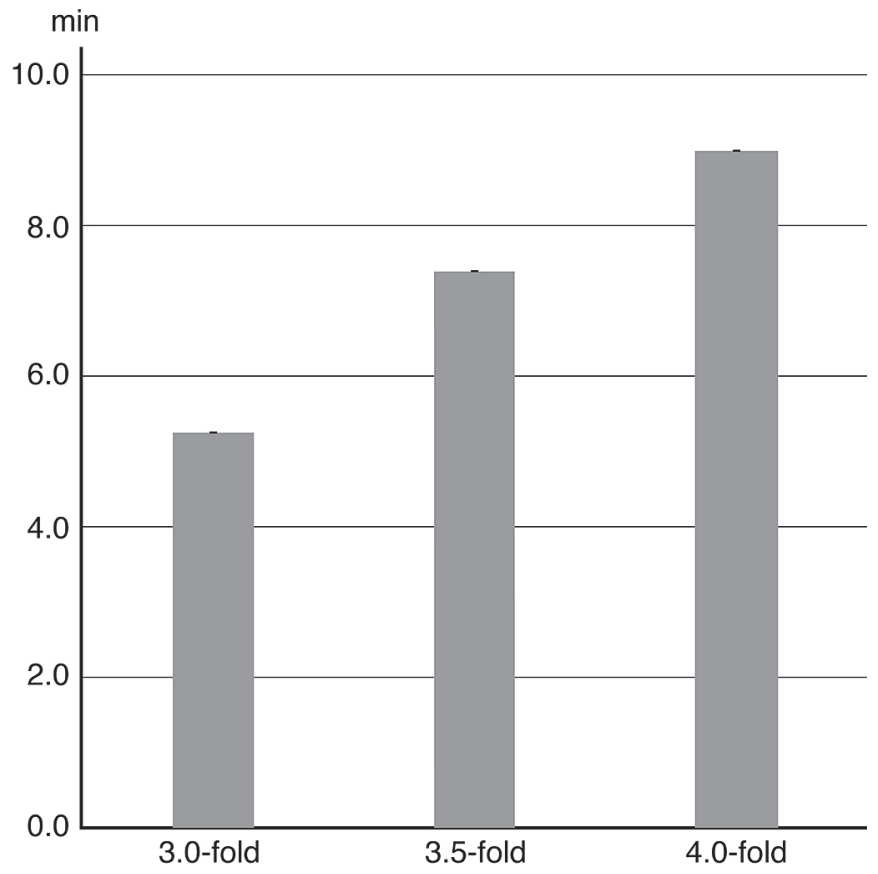

Figure 4. Setting time of the BCP-cement. The cement showed injectable phase initially and exhibited moldable phase, and then hardened stiffly. The 3.0-fold sample showed the shortest setting time until the hardening among all samples, and there were apparent differences between each sample in hardening $(p<0.05)$.

\section{Mechanical strengths}

Mechanical strengths of the samples are shown in Figs. 5 and 6. Mean one-day wet DTS $(n=4)$ values were 3.0 -fold: $7.07 \pm 0.51 \mathrm{MPa}, 3.5$ fold: $5.98 \pm 0.91 \mathrm{MPa}$ and 4.0 -fold: $5.07 \pm 0.51 \mathrm{MPa}$, and CS values were 3.0-fold: $46.58 \pm 3.21 \mathrm{MPa}, 3.5$-fold: $47.75 \pm 2.55 \mathrm{MPa}$ and 4.0 -fold: $45.53 \pm 1.97 \mathrm{MPa}$.

DTS results showed that 3.0-fold sample exhibited the largest DTS value in all samples and a clear difference existed between it and 4.0fold sample $(p<0.05)$. No clear difference existed between 3.0-fold and 3.5 -fold cement samples and also 3.5 -fold to 4.0 -fold samples. CS results showed no apparent difference existed among all samples $(p<0.05)$.

\section{XRD analysis}

Powder XRD patterns of 3.0-fold/3.5-fold/4.0-fold samples at $24 \mathrm{~h}$ are shown in Fig. 7. The diffraction patterns of all the $24 \mathrm{~h}$ samples exhibited that the detection intensities and peaks of HA were quite similar to those of standard powder X-ray diffraction data (Powder Diffraction File: PDF). No apparent difference was found among the samples. 


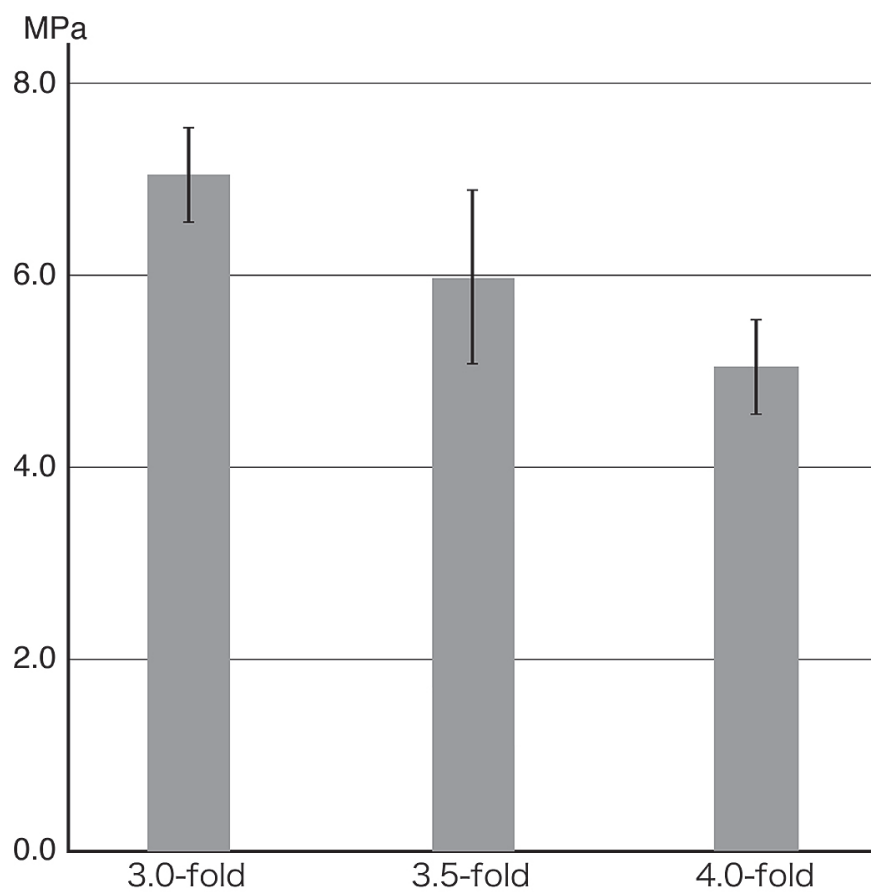

Figure 5. Diametral tensile strength (DTS) of the BCP cement. DTS results showed that 3.0-fold sample exhibited the largest DTS value in all samples and a clear difference existed between it and 4.0 -fold sample $(p<0.05)$. No clear difference existed between 3.0-fold and 3.5-fold cement samples and also 3.5 -fold to 4.0 -fold samples.

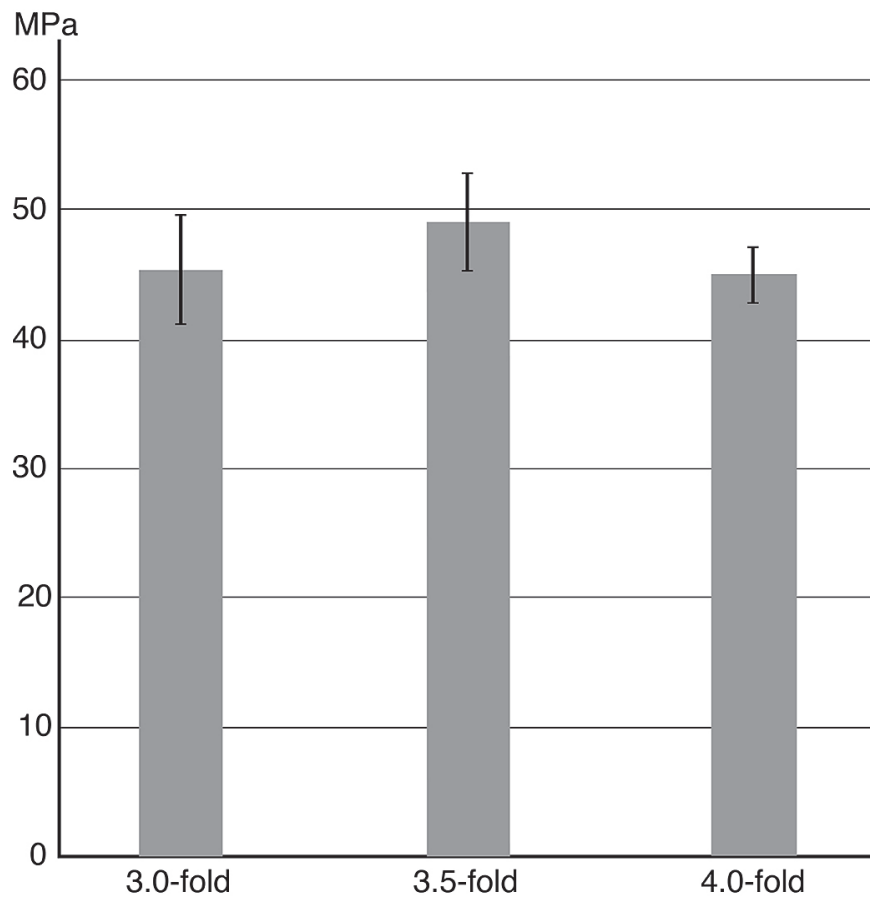

Figure 6. Compressive strength (CS) of the BCP-cement. CS results showed no apparent difference existed among all samples $(p<0.05)$.

The $\alpha$-TCP and TTCP diffraction patterns of 3.5 -fold samples at 6 , 12,24 and $48 \mathrm{~h}$ were reduced and that of HA was clearly detected in $6 \mathrm{~h}$ samples. The diffraction pattern of $12 \mathrm{~h}$ sample showed that HA was the main phase (Fig. 8). The diffraction pattern of $48 \mathrm{~h}$ sample exhibited
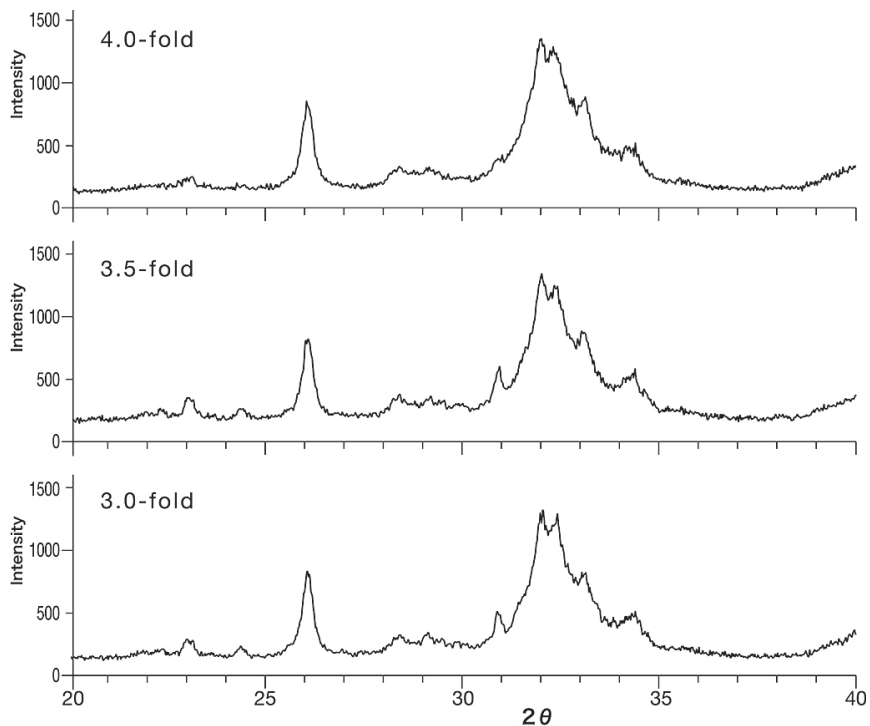

Figure 7. XRD patterns of 3.0-/3.5-fold/4.0-fold samples at $24 \mathrm{~h}$. The diffraction patterns of all the $24 \mathrm{~h}$ samples exhibited that the detection intensities and peaks of HA were quite similar to those of standard powder X-ray diffraction data (Powder Diffraction File: PDF). No apparent difference was found among the samples.

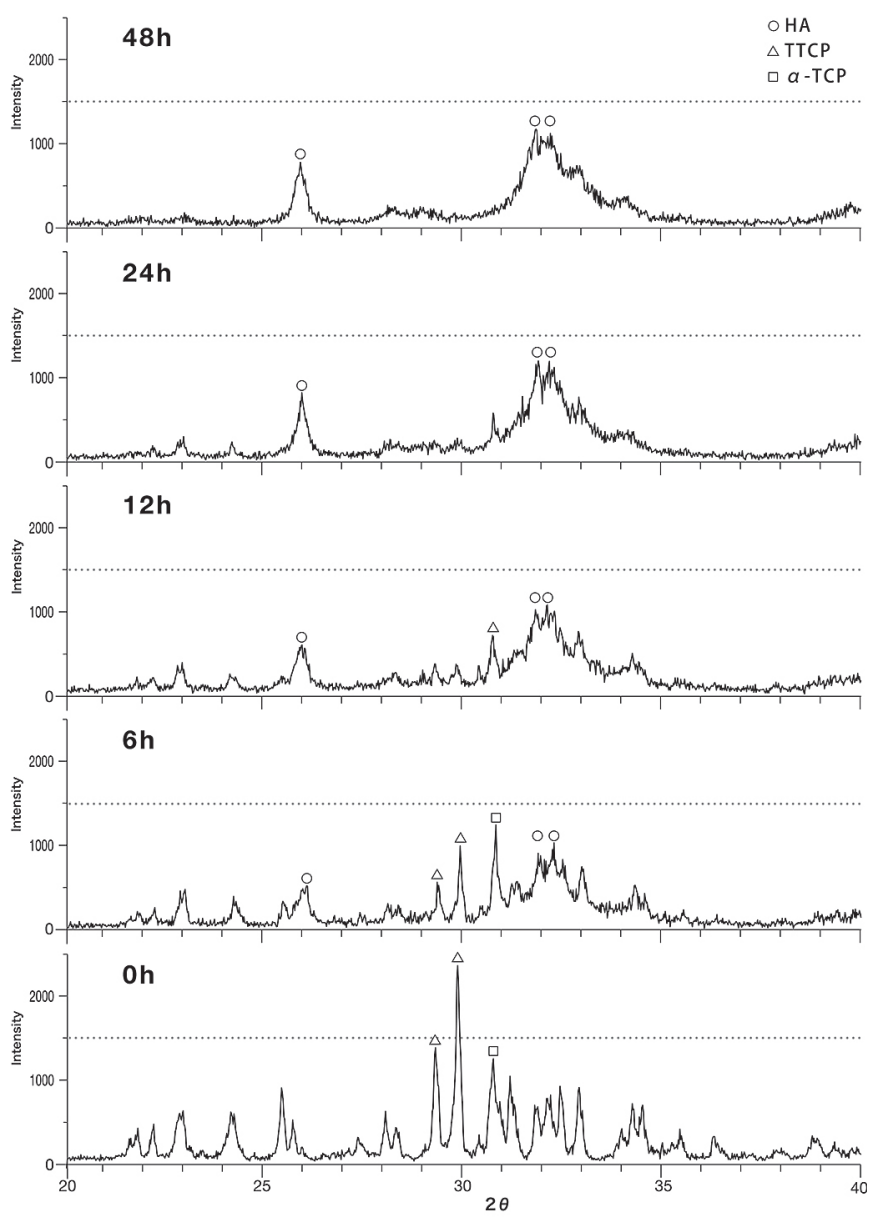

Figure 8. XRD patterns of the 3.5-fold samples at 6, 12, 24 and $48 \mathrm{~h}$. The BCP cement formed HA chronologically and was mostly converted to HA after $24 \mathrm{~h}$ from mixing. 

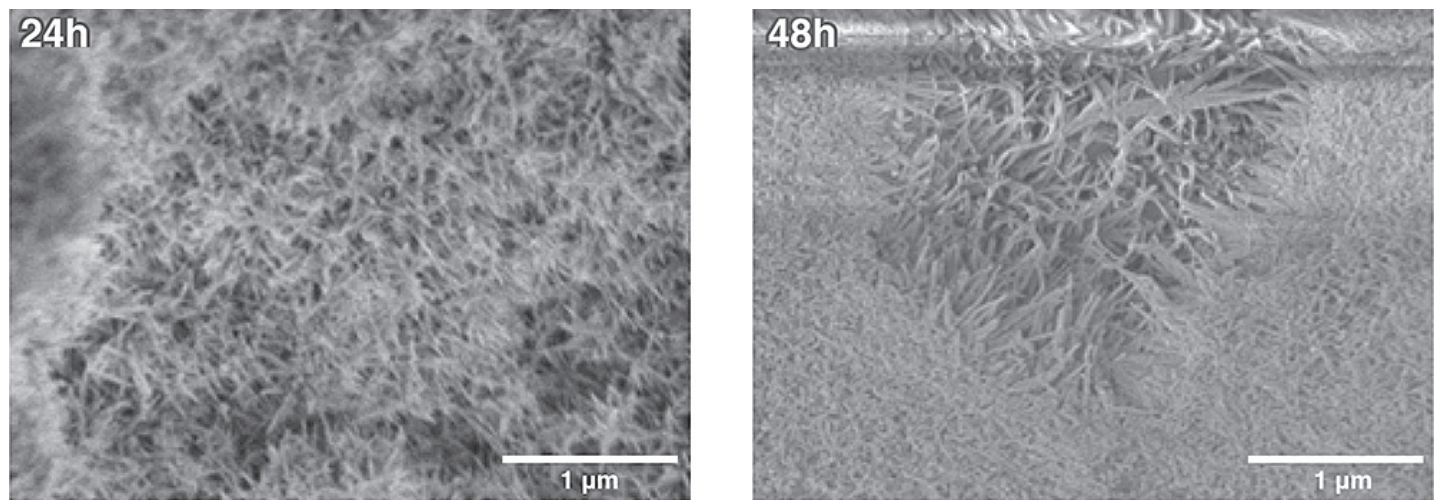

Figure 9. FE-SEM micrographs of fracture surfaces of $24 \mathrm{~h}$ and $48 \mathrm{~h}$ samples. HA crystals were already found on the fracture surface of the $24 \mathrm{~h}$ sample, and apparent needle and rod shape crystals were clearly formed on the surface of the $48 \mathrm{~h}$ sample.
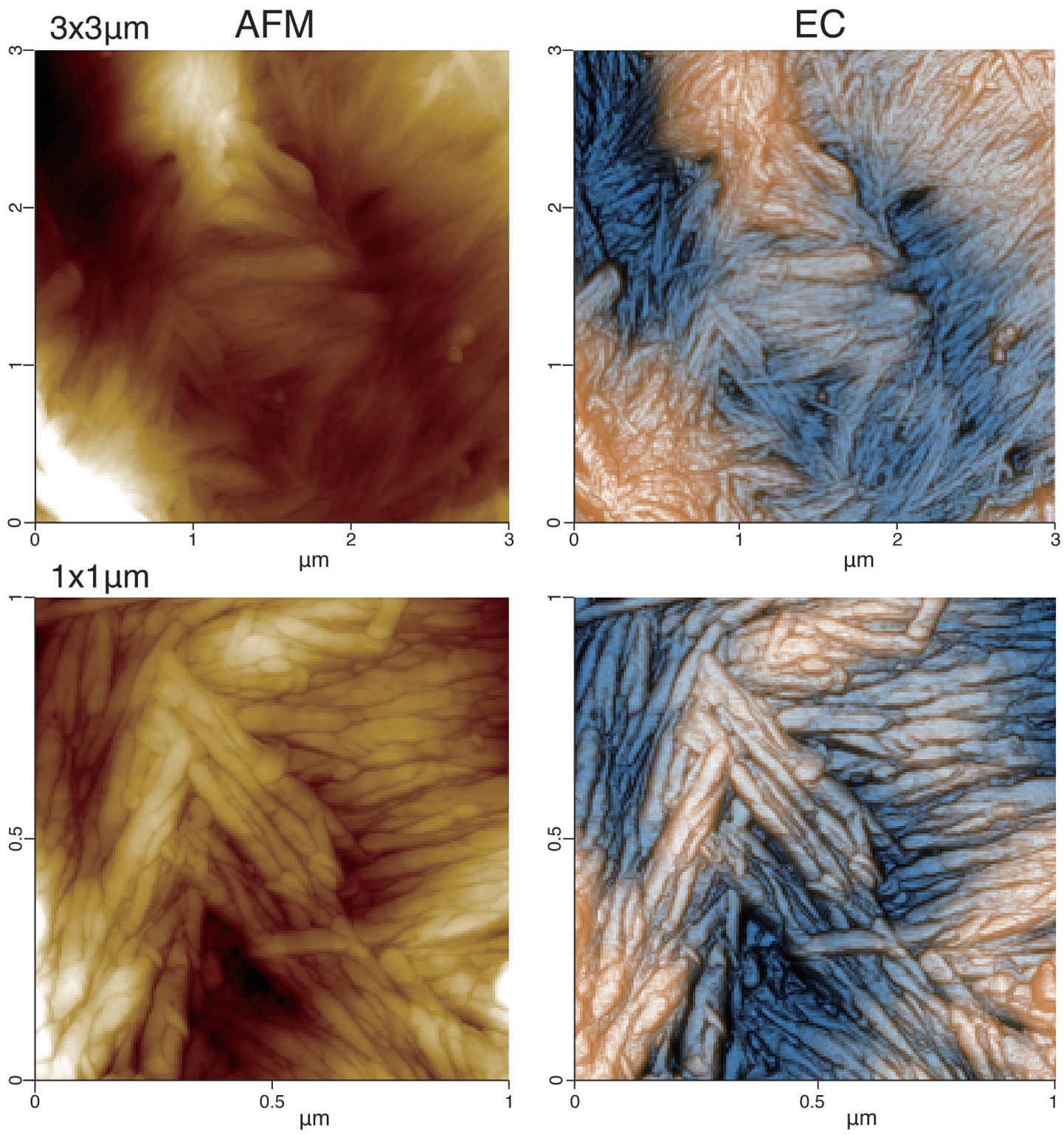

Figure 10. AFM images of $24 \mathrm{~h}$ sample. In the $3 \times 3 \mu \mathrm{m}$ image, fine HA crystals were formed on the entire surface and did not show constant regular arrangement or orientation. As was clear from the $1 \times 1 \mu \mathrm{m}$ enlarged image, HA crystals were clearly observed with fine crystallinity and the crystal size of the HA was approximately $20-50 \mathrm{~nm}$ in diameter and $200-400 \mathrm{~nm}$ in length. 
that the intensities and peaks of HA were clearly observed compared with those of $24 \mathrm{~h}$ sample. Very small amounts of unreacted $\alpha$-TCP and TTCP were still found in $24 \mathrm{~h}$ and $48 \mathrm{~h}$ samples. XRD results indicated that the BCP cement formed HA within $6 \mathrm{~h}$ and changed into HA chronologically. It was nearly completely converted to HA after $24 \mathrm{~h}$ from mixing.

\section{Microscopic observations}

FE-SEM micrographs of fracture surfaces of the sample at $24 \mathrm{~h}$ and $48 \mathrm{~h}$ are shown Fig. 9. Small HA crystals were already found on the fracture surface of the $24 \mathrm{~h}$ sample, and apparent needle and rod shape crystals were clearly formed on the surface of the $48 \mathrm{~h}$ sample. FE-SEM images not only revealed the presence of HA crystals in the formed samples, but also showed clearly that the density of HA crystals increased with the increase of HA content.

Figs. 10 and 11 show the observed AFM images of $24 \mathrm{~h}$ and $48 \mathrm{~h}$ samples. In the $3 \times 3 \mu \mathrm{m}$ image of Fig. 10 , it was confirmed that fine nee- dle shape HA crystals were formed on the entire surface of the $24 \mathrm{~h}$ sample. It was clearly confirmed by EC that there were some crystals in the region where observation was difficult by AFM. As was clear from the $1 \times 1 \mu \mathrm{m}$ enlarged image, HA crystals were clearly observed with fine crystallinity. The crystal size of HA observed in the $24 \mathrm{~h}$ sample was approximately $20-50 \mathrm{~nm}$ in diameter and $200-400 \mathrm{~nm}$ in length. In addition, it was confirmed that the HA crystals did not show constant regular arrangement or orientation. In the $3 \times 3 \mu \mathrm{m}$ image of Fig. 11, the $48 \mathrm{~h}$ sample showed that larger density and more matured HA crystals formed on whole surface in comparison to the $24 \mathrm{~h}$ sample. The $1 \times 1 \mu \mathrm{m}$ image exhibited that excellent cylindrical crystalline structures were formed on whole surface.

FE-SEM and AFM images of the 3.0- and 4.0-fold cement samples taken in additional FE-SEM and AFM experiments at $24 \mathrm{~h}$ and $48 \mathrm{~h}$ exhibited quite similar to those of the 3.5 -fold sample at $24 \mathrm{~h}$ and $48 \mathrm{~h}$.


Figure 11. AFM images of $48 \mathrm{~h}$ sample. In the $3 \times 3 \mu \mathrm{m}$ image, the sample showed that larger density and more matured HA crystals formed on whole surface in comparison to the $24 \mathrm{~h}$ sample. The $1 \times 1 \mu \mathrm{m}$ image exhibited that excellent cylindrical crystalline structures were formed on whole surface. 


\section{Discussion}

Previous studies ${ }^{19-33)}$ have reported that the conventional CPCs were excellent materials for reconstructive surgery for alveolar bone deficiencies, orthopedic, and maxillofacial surgical applications, because most of CPCs formed low crystalline HA which was main inorganic component of bone. CPCs undergo the process of biodegradable and bioresorbable nature in vivo, so they work effectively for bone substitute materi$\mathrm{als}^{31)}$. On the other hand, CPCs still had some difficulties for maintaining the original grafted shape and volume at defect site, because they did not have enough washout resistance and viscosity in body fluid ${ }^{6,31,32)}$. These properties were caused by physical flow and chemical dissolution of the material components in the body fluid. Some CPCs took a long time to harden and showed inadequate physical properties and HA conversion for clinical uses even at $24 \mathrm{~h}$ after mixing. They also lack adequate controlled degradability for bone formation when implanted in the bone defect.

Therefore, a new bone substitute material was required to have sufficient physical strength and appropriate cellular affinity along with biodegradable and bioresorbable potential to facilitate the bone remodeling process $^{31}$. Above those reasons, we developed the BCP cement with improved washout resistance in body fluid, handling properties, mechanical strengths and rapid HA conversion compared to the conventional cements ${ }^{6-16}$. In this experiment, physical properties of $\mathrm{BCP}$ cements when used the Ca-P soln diluted with 3.0, 3.5 or 4.0-fold of $\mathrm{H}_{2} \mathrm{O}$ and mixed at $\mathrm{P} / \mathrm{L}$ ratio of 3.0, such as DTS, CS, setting time and washout resistance, were examined. All BCP cements showed excellent washout resistance when immersed in water and set stiffly within 10 minutes. All BCP cements also showed almost same mechanical strengths, diffraction patterns of XRD and microscopic features. Even until the hardening, the cement paste kept original shape and did not visibly disintegrate in water. After the hardening, the BCP cement had sufficient mechanical strength for various clinical applications.

Based on the mode of bone reaction against HA in the in vivo environment, high temperature HA (HT-HA) with high crystallinity is reported to be suitable for HA coating for implant surfaces due to exhibiting osteoconductivity as a result of its bioactive/non-bioresorbable nature ${ }^{33)}$. Low temperature HA (LT-HA) with low crystallinity produced at room temperature is reported to be suitable as a bone graft material due to bone substitution properties given by its bioactive/bioresorbable nature ${ }^{6,31-33)}$. When the hardening reaction of the $\mathrm{BCP}$ cement proceeded, the BCP cement gradually formed HA and was mostly converted to LT-HA, which is the main inorganic component of bone, as the final product within $24 \mathrm{~h}$ after the mixing ${ }^{7-10)}$. Therefore, the cement may show superior biocompatibility and osteoconductivity ${ }^{6,8,11-13,15)}$. HA crystals formed from the BCP cement were low-crystallinity and nano-meter size, which are the magnitude of those contained in bone, so it might be assumed that the HA crystals could be easily resorbed by osteoclasts and converted to natural bone, as which spontaneously occurred in bone remodeling ${ }^{31-34)}$.

Our former study reported that the BCP cement, which was used for artificially created critical bone defects in rat calvaria, combined to residual bone firmly and converted to natural bone chronologically ${ }^{6}$. This binding between the BCP cement and the residual bone increased the mechanical strength of the filling material and reduced its susceptibility to infections ${ }^{6-8,11,12)}$. A recent study also reported that the BCP cement formed approximately $5 \mathrm{wt} \%$ B-type carbonate apatite $\left(\mathrm{CO}_{3}\right.$-AP), essentially existing at $5-8 \mathrm{wt} \%$ in natural bone, when implanted in subcutaneous tissues of rat for 8 weeks ${ }^{15}$. These reports also explained that the BCP cement should convert to low crystalline HA like natural bone.
The BCP cement had superior handling properties and hardened stiffly and rapidly. It also showed excellent washout resistance and shape integrity in aqueous solution. Therefore, the BCP cement successfully retained the original graft shape ${ }^{6-8)}$. The BCP cement also had adequate physical properties and mostly converted to HA within $24 \mathrm{~h}$. These results strongly indicate that $\mathrm{BCP}$ cement could be an effective and suitable material for clinical uses.

\section{Acknowledgements}

The authors would like to give cordial thanks to Dr. Masahiro Kaketani, Department of Dental Materials, Nihon University School of Dentistry, and Mr. Hiroaki Okano, Taihei Chemical Industrial Co. Ltd, for their technical supports.

\section{Conflict of Interest}

The author has declared that no COI exists.

\section{References}

1. Brown WE and Chow LC. Dental restoration cement pastes. US Patent: Patent No.4518430, 1985

2. Dorozhkin SV. Self-setting calcium orthophosphate formulations. J Funct Biomater 4: 209-311, 2013

3. Schmitz JP, Hollinger JO and Milam SB. Reconstruction of bone using calcium phosphate bone cements: a critical review. J Oral Maxillofac Surg 57: 1122-1126, 1999

4. Sariibrahimoglu K, Wolke JG, Leeuwenburgh SC, Yubao L and Jansen JA. Injectable biphasic calcium phosphate cements as a potential bone substitute. J Biomed Mater Res B Appl Biomater 102B: 415-422, 2014

5. Tagaya M, Goto H, IInuma M, Wakamatsu N and Tamura Y. Development of self setting Te-CP/ $\alpha$-TCP cement for pulpotomy. Dent Mater J 24: 555-561, 2005

6. Sugawara A, Fujikawa K and Sato S. Evalution of biphasic calcium phosphate cement in rat calvarial model. J Hard Tissue Biology 27: 109-116, 2018

7. Sugawara A. Method for controlling work time for forming shape of biphasic self-setting calcium phosphate. US Patent: No.10322211, 2019

8. Sugawara A. Method for controlling work time for forming shape of biphasic self-setting calcium phosphate. Japanese Patent: No. 6490050,2015

9. Hirayama S, Sugawara A, Fujikawa K, Okano H and Hirano A. Biphasic calcium phosphate based fast self-setting calcium phosphate cement. J Dent Res (Spec Iss A): 2368, 2015

10. Hirayama S, Iwai H, Sugawara A, Fujikawa K, Hirano A. Physical properties of biphasic calcium phosphate cements (abstract 3103). Jpn J Conserv Dent, Program, 103, 2016 (in Japanese)

11. Sugawara A, Fujikawa K, Koshi R, Ozawa Y, Kubota T, Yamamoto $\mathrm{T}$ and Sato $\mathrm{S}$.

Evaluation of biphasic calcium phosphate-based cement in rat calvarial model. J Dent Res (Spec Iss A): 3557, 2015

12. Tsukune N, Sugawara A, Fujikawa K, Hirano A, Yamamoto T and Sato S. Osteoconductivity of BCP cement when used for calvarial bone defect of rats. J Dent Res 96 (Spec Iss A): 1925, 2017

13. Ozawa Y, Koshi R, Kubota T, Yamamoto T, Sugawara A, Fujikawa $\mathrm{K}$ and Sato $\mathrm{S}$. A new generation bone substitute materials: Histopathological evalution of biphasic calcium phosphate-based cement in rat calvarial model (abstract 2504). Jpn J Conserv Dent, Program, 
156, 2016 (in Japanese)

14. Fujikawa K, Sugawara A, Hirano A, Tohyama M, Hayashi M. Histopathological reactions and $\mathrm{CO} 3-\mathrm{AP}$ formation of $\mathrm{BCP}-$ cement in subcutaneous tissues. J Dent Res 98 (Spec Iss A): 2523, 2019

15. Fujikawa $\mathrm{K}$ and Sugawara A. Histopathological evaluation of BCP-cement on rat calvarial mode. J Dent Res 99 (Spec Iss A): 866, 2020

16. Sugawara A and Fujikawa K. Physical properties and hydroxyapatite formation of biphasic calcium phosphate cement. (abstract 2497). J Dent Res 99 (Spec Iss A): 2497, 2020

17. Sugawara A, Yamamoto T, Fujikawa K, Hirano A, Koshi R and Sato S. Evaluation of TCP-TTCP Cement in Rat Calvarial Model (abstract 1926). J Dent Res (Spec Iss A): 184, 2017

18. Carey LE, Xu HHK, Simon Jr CG, Takagi S and Chow LC. Premixed rapid-setting calcium phosphate composites for bone repair. Biomater 26: 5002-5014, 2005

19. Takagi S, Chow LC, Hirayama S and Sugawara A. Premixed calcium phosphate cement pastes. J biomed Mater Res (Appl Biomater) 67B: 689-696, 2003

20. Xu HHK, Takagi S Quinn JB and Chow LC. Fast-setting calcium phosphate scaffolds with tailored macropore formation rates for bone regeneration. J Biomed Mater res 68A: 725-734, 2004

21. Chow LC, Takagi S, Costantino PD and Friedman CD. Self-setting calcium phosphate cements. Mater Res Soc Symp Proc 179: 3-24, 1991

22. Sugawara A, Nishiyama M, Kusama K, Moro I, Nishimura S, Kudo I, Chow LC and Takagi S. Histopathological reactions of calcium phosphate cement. Dent Mater J 11: 11-16, 1992

23. Sugawara A, Kusama K, Nishimura S, Nishiyama M, Moro I, Kudo I, Takagi S and Chow LC, Histopathological reactions to calcium phosphate cement for bone filling. Dent Mater J 12: 691-698, 1993

24. Sugawara A, Kusama K, Nishimura S, Nishiyama M and Moro I. Histopathological reactions of a calcium phosphate cement root ca- nal filler. J Hard Tissue Biol 4: 1-7, 1995

25. Fujikawa K, Sugawara A, Murai S, Nishiyama M, Takagi S and Chow LC. Histopathological reaction of calcium phosphate cement in periodontal bone defect. Dent Mater J 14: 45-57, 1995

26. Sugawara A, Fujikawa K, Kusama K, Nishiyama M, Murai S, Takagi $\mathrm{S}$ and Chow LC. Histopathlogical reaction to calcium phosphate cement for alveolar ridge augmentation. J Biomed Mater Res 61: 47-52, 2002

27. Fujikawa K, Sugawara A, Kusama K, Nishiyama M, Murai S, Takagi $\mathrm{S}$ and Chow LC. Fluorescent labeling analysis and electron probe microanalysis for alveolar ridge augmentation using calcium phosphate cement. Dent Mater J 21: 296-305, 2002

28. Takagi S, Chow LC, Hirayama S and Sugawara A. Premixed calcium-phosphate cement pastes. J Biomed Mater Res B Appl Biomater 67B: 689-696, 2003

29. Sugawara A, Fujikawa K, Takagi S, Chow LC, Nishiyama M and Murai S. Histopathological and cell enzyme studies of calcium phosphate cements. Dent Mater J 23: 613-620, 2004

30. Sugawara A, Fujikawa K, Takagi S and Chow LC. Histological analysis of calcium phosphate bone grafts for surgically created periodontal bone defects in dogs. Dent Mater J 27: 787-794, 2008

31. Sugawara A. Bone Regeneration Technology: Newly Revised Edition - Concept and Clinical Application of Bone Regeneration. Zenith Press, Tokyo, 2011. (in Japanese)

32. Sugawara A. Evidential Implantology. Zenith Press, Tokyo, 2013. (in Japanese)

33. Sugawara A. AFM observations and composition analyses of the top surfaces of HA implants. J Hard Tissue Biology 26: 331-346, 2017

34. Zeeshan, Mohamed-Nur Abdallah, Ahmed Abdalla Hanafi, Syed Misbahuddin, Haroon Rashid and Michael Glogauer. Mechanisums of in vivo degradation and resorption of calcium phosphate based biomaterials. Materials 8: 7918-7925, 2015 
J.Hard Tissue Biology Vol. 29(3): 173-182, 2020 